\title{
Fabrication and Mechanical Properties of Glass Fiber Epoxy Reinforced with $\mathrm{Al}_{2} \mathrm{O}_{3}$ Particles
}

\section{Authors}

\author{
Kunjan Kumar Chaudhary ${ }^{1}$, Anuj Kumar ${ }^{2}$, Indra Prakash ${ }^{3}$ \\ ${ }^{1}$ B.Tech+M.Tech Student, NIMS University Jaipur, \\ ${ }^{2}$ Assistant Professor, Dept.of Mechanical Engineering, \\ ${ }^{3}$ Assistant Professor, Dept. of Petroleum Engineering
}

Email: kunjankchaudhary@gmail.com, anuj.anuj07@gmail.com,inderprakash09@gmail.com

\begin{abstract}
Composite materials and layered structure based glass fibers are increasingly regarded as an alternative to $\mathrm{Al}_{2} \mathrm{O}_{3}$ reinforced parts. It can used in many fields of application such as structural components for the automotive industry. Glass fiber can be used as an alternative material in present world in many fields, such as manufacturing of Boats and Marine, Home, Leisure, Electronics, sport industry, Medical etc. The aim of this study is to determine the mechanical properties of glass fibre epoxy composites plates by varying percentage of $\mathrm{Al}_{2} \mathrm{O}_{3}$. The composite plates were fabricated by hand layup techniques which is very economical. The flexural property under three point bend test is investigated experimentally by using the theory of failure. Experimental result reveals that the percentage of $\mathrm{Al}_{2} \mathrm{O}_{3}(0,5,10 \& 15 \mathrm{wt}$. \%) increases strength and hardness of material comparatively. Charpy's Impact test is performed to assess the shock absorbing capability of material.
\end{abstract}

Keywords- Hand lay-up, composite laminates, load carrying capacity, impact energy.

\section{INTRODUCTION}

Composites are the material used in various fields having exclusive mechanical, physical properties and are developed for particular application. The development of composite materials and their related design and manufacturing technologies is one of the most important advances in the history of materials. Composite materials having a range of advantages over other conventional materials such as tensile strength, impact strength, flexural strengths, stiffness and fatigue characteristics. Because of their numerous advantages they are widely used in the aerospace industry, commercial mechanical engineering applications, like machine components, automobiles, combustion engines, tanks, brakes, pressure vessels and flywheels, thermal control and electronic packaging, railway coaches and aircraft structures. When two or more materials with different properties are combined together, they form a composite material. Composite material comprise of strong load carrying material (known as reinforcement) imbedded with weaker materials (known as matrix). The primary functions of the matrix are to transfer stresses between the reinforcing fibres/particles and to protect them from mechanical and/or environmental damage whereas the presence of fibres particles in a composite improves its mechanical properties like tensile strength, flexural strength, impact strength, stiffness etc. The properties of a composite material depend on the properties of the constituents, geometry and distribution of the phases. One of the most important parameters is the volume (or weight) fraction of reinforcement, or fiber volume ratio. The distribution of the reinforcement determines the homogeneity or uniformity of the material system. The most nonuniformity is the reinforcement distribution, if more heterogeneous material then the higher the probability of failure in the weakest areas. The 
geometry and orientation of the reinforcement affect the anisotropy of the system. The phases of the composite system have different roles that depend on the type and application of the composite material. In the case of low to medium performance composite materials, the reinforcement, usually in the form of short fibres and particles, provides some stiffening but only local strengthening of the material. The matrix, on the other hand, is the main load-bearing constituent governing the mechanical properties of the material. In the case of high performance structural composites, the usually continous-fiber reinforcement is the backbone of the material that determines its stiffness and strength in the direction of fibres. The matrix phase provides protection and support for the sensitive fibres and local stress transfer from one fiber to another. The interphase although small in size, can play an important role in controlling the failure mechanisms, fracture toughness, and overall stress-strain behaviour of the material.

\section{OBJECTIVE}

To study the effect of $\mathrm{Al}_{2} \mathrm{O}_{3}$ percentage on mechanical behaviour of glass fiber reinforced epoxy based composites.

Evaluation of mechanical properties such as compressive strength, flexural strength, impact strength etc.

Fabrication of new class of epoxy based $\mathrm{Al}_{2} \mathrm{O}_{3}$ composite reinforced with bi-directional glass fibers.

\section{METHODOLOGY}

\section{Composite Fabrication}

In room temperature epoxy resin used as matrix material and the hardener are mixed in ratio of 10:1.34 by weight recommended. Solid aluminium are reinforced in the resin to prepare the composites.

\begin{tabular}{|c|c|c|}
\hline Sr. No. & Name & Chemical Name \\
\hline 1 & Resin Used & Epoxy Resin \\
\hline 2 & Hardener Used & $\begin{array}{c}\text { Mekp (methyl ethyl } \\
\text { ketone peroxide) }\end{array}$ \\
\hline 3 & $\begin{array}{c}\text { Percentage of } \\
\text { Hardener }\end{array}$ \\
\hline 4 & $\begin{array}{c}\text { Percentage of } \\
\text { Aluminium Oxide } \\
\text { (Al2O3) }\end{array}$ & $\begin{array}{c}5 \%, 10 \% \text { and } 15 \% \mathrm{wt} . \\
\text { of resin }\end{array}$ \\
\hline
\end{tabular}

During the preparation of solution (epoxy resin + Hardener + Aluminium Oxide ) we have to be careful on mixing ratio. If the hardener ratio is more in resin the solution will become hard within 5 minutes. While, if the hardener ratio is low then our final product will not become hard.

\section{Hand Layup Technique}

The oldest and simplest moulding technique in which reinforcing materials and catalyzed resin are laid into or over a mould by hand. These materials are then compressed with a roller to eliminate trapped air. Following are the processesused here for the fabrication of Glass fiber reinforced composite laminates.

- Clean the mould with cotton cloth.

- Remove the unwanted resin and gelcoat present on the mould of previous trip.

- Do the papering of the mould with hot water if necessary.

- Wipe out the water with dry cotton cloth till the moisture is totally removed.

- Apply mansion wax polish and remove with cotton cloth.

- Wait for 2-5 min and then apply P.V.A

- After P.V.A is dry apply first coat of gelcoat and wait till it get gelled.

- Apply second coat of gelcoat and wait till it gets gelled.

- Apply resin coating and immediately place glass fibre. Again apply resin coating over the glass fibre.

- Impregnate it using roller to remove air bubbles.

- Repeat the previous three process to get the desired thickness of the laminate. 


\section{EXPREMENTALWORK}

\section{Three Point Beam Test}

Flexural strength, also known as modulus of rupture, bend strength, or fracture strength a mechanical parameter for brittle material, is defined as a material's ability to resist deformation under load. The transverse bending test is most frequently employed, in which a rod specimen having either a circular or rectangular crosssection is bent until fracture using a three point flexural test technique. The flexural strength represents the highest stress experienced within the material at its moment of rupture.

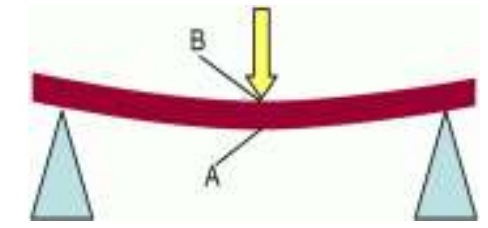

Figure 1 Beam under 3 point bending

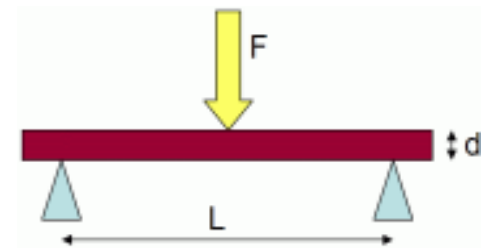

Figure 2 Beam of material under bending.

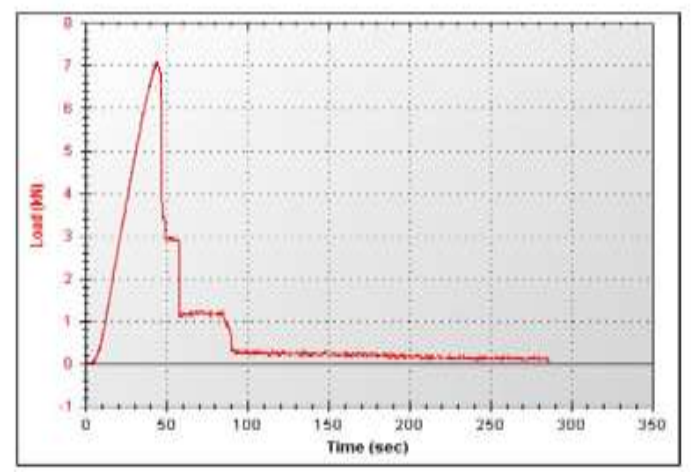

Figure 3 Load vs Time Graph

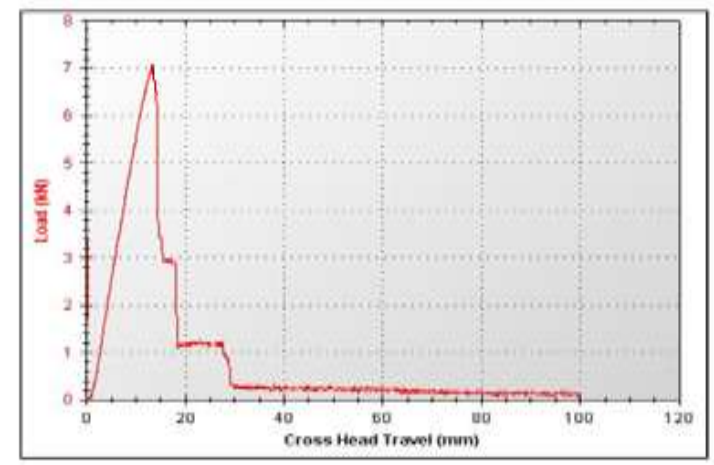

Figure 4 Load vs Elongation Graph

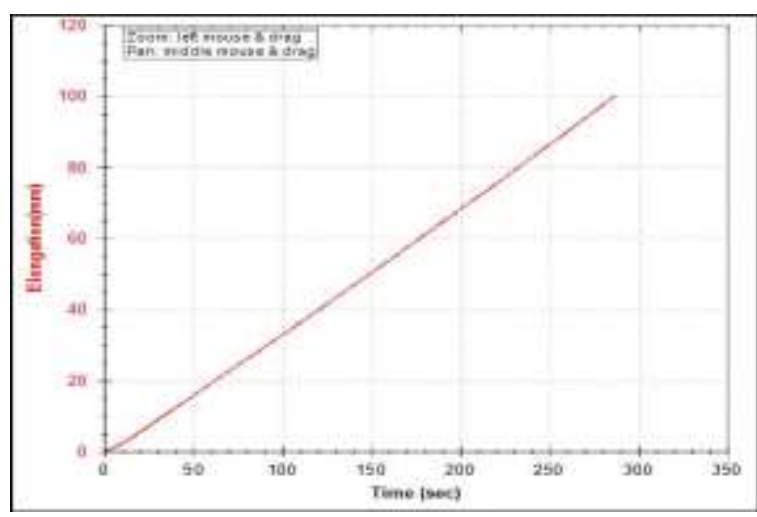

Figure 5 Elongation vs Elapsed Time Graph

\section{Charpy Impact Test}

The charpy impact test, also known as the charpy v-notch test, is a standardized high strain-rate test which determines the amount of energy absorbed by a material during fracture. This absorbed energy is a measure of a given material's toughness and acts as a tool to study temperaturedependent brittle-ductile. It is widely applied in industry, since it is easy to prepare and results can be obtained quickly and cheaply. The notch in the sample affects the results of the impact test, thus it is necessary for the notch to be of regular dimensions and geometry. The size of the sample can also affect results, since the dimensions determine whether or not the material is in plane strain.

\section{RESULT AND DISCUSSION MECHANICAL CHARACTERISTICS OF COMPOSITES:}

This chapter presents the mechanical properties of the glass fiber reinforced epoxy composites prepared by varying $\left(\mathrm{Al}_{2} \mathrm{O}_{3}\right)$ percentage for the present investigation. The results of various characterization tests are reported here. This includes evaluation of compressive strength, flexural strength; impact energy. The interpretation of the results and the comparison among various composite samples are also presented.

(a) Effects of varying percentage of Aluminium Oxide $\left(\mathrm{Al}_{2} \mathrm{O}_{3}\right)$ on Flexural Strength

The graph shows that the flexural strength of specimen increases with increasing Aluminium oxide $\left(\mathrm{Al}_{2} \mathrm{O}_{3}\right)$ percentages between $5-10 \%$ and 
gives increasing value from $123.049 \mathrm{~N} / \mathrm{mm}^{2}$ to $138.409 \mathrm{~N} / \mathrm{mm}^{2}$. When Aluminium oxide $\left(\mathrm{Al}_{2} \mathrm{O}_{3}\right)$ percentage varying from $10-15 \%$ flexural strength value increasing $158.522 \mathrm{~N} / \mathrm{mm}^{2}$ to $120 \mathrm{~N} / \mathrm{mm}^{2}$. Thus result shows better flexural strength near $15 \%$ Aluminium Oxide with respect to thickness.

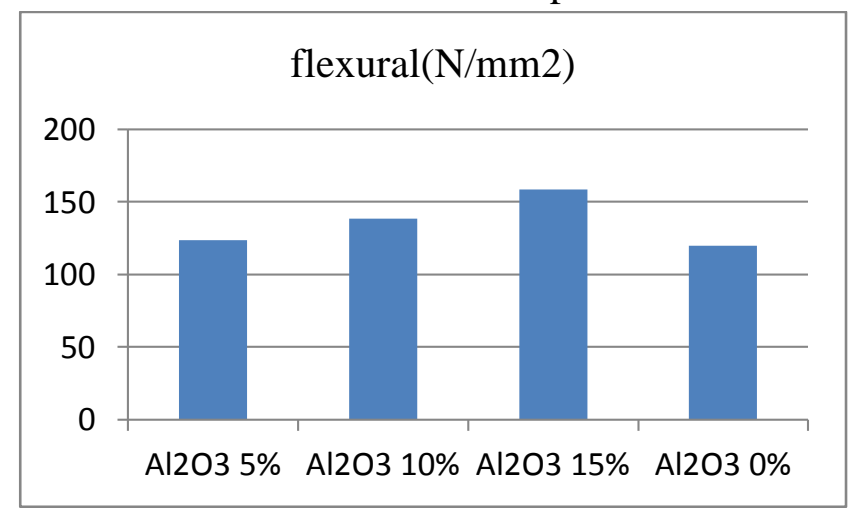

Figure 6 Graph between flexural strength and $\mathrm{Al}_{2} \mathrm{O}_{3}$

b) Effect of varying percentage of Aluminium Oxide $\left(\mathrm{Al}_{2} \mathrm{O}_{3}\right)$ on compressive strength

The compression test of specimen was performed on UTM machine TUE-C-400. The graph shows that the compressive strength increases with the increasing Aluminium Oxide $\left(\mathrm{Al}_{2} \mathrm{O}_{3}\right)$ percentage between $5-10 \%$ and compressive strength value increases from 6.26 to $6.858 \mathrm{~N} / \mathrm{mm}^{2}$. On the other hand compressive strength value increases from 6.858 to $7.15 \mathrm{~N} / \mathrm{mm}^{2}$ with varying $\mathrm{Al}_{2} \mathrm{O}_{3}$ percentage from $10-15 \%$.

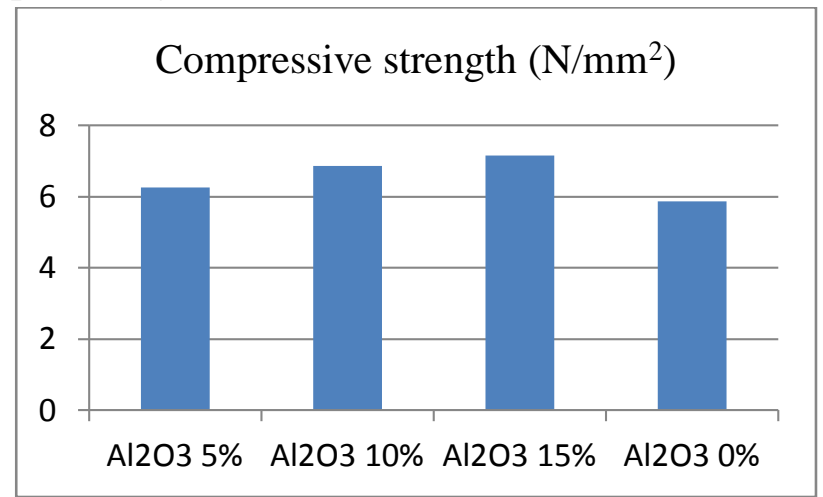

Fig 7 Graph between Compressive Strength and $\mathrm{Al}_{2} \mathrm{O}_{3} \%$

(c) Effect of varying percentage of Aluminium Oxide $\left(\mathrm{Al}_{2} \mathrm{O}_{3}\right)$ on Impact strength

The impact energy value of different composite recorded during charpy impact test in table. It shows that the resistance to impact loading of
Aluminium Oxide reinforced epoxy composite increasing in varying $\mathrm{Al}_{2} \mathrm{O}_{3}$ ) percentage from 5$10 \%$ and gives the value 55 Joule to 80 Joule. And again increasing with increase in $\mathrm{Al}_{2} \mathrm{O}_{3}$ percentage $10-15 \%$, it shows impact strength value 80 to 95 joule. High strain rates or impact loads may be expected in many engineering applications of composite materials. The suitability of a composite for such applications should therefore be determined not only by usual design parameters, but by its impact or energy absorbing properties.

From the above discussion better flexural strength and compressive strength comes in the range of Al2O3 percentage $10-15 \%$. And better impact strength comes near $15 \%$ of Aluminium Oxide $\left(\mathrm{Al}_{2} \mathrm{O}_{3}\right)$ with respect to total thickness of specimen.

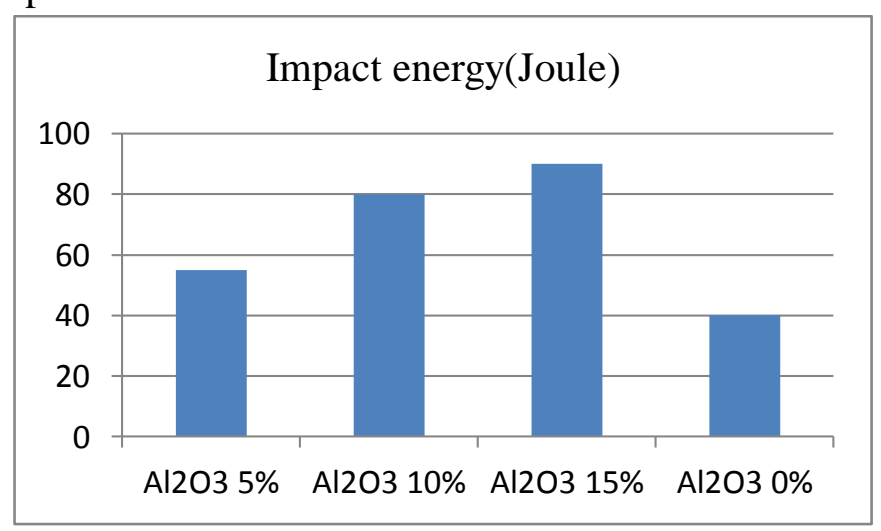

Fig 8 Graph between Impact Energy and $\mathrm{Al}_{2} \mathrm{O}_{3} \%$

\section{CONCLUSION}

The investigation of mechanical behaviour of Glass fiber reinforced epoxy composites leads to the following conclusions:

This work reveals that successful fabrication of a Glass fiber reinforced epoxy composites with varying percentage Aluminium Oxide $\left(\mathrm{Al}_{2} \mathrm{O}_{3}\right)$ is possible by simple hand lay-up technique

It has been noticed that the mechanical properties of the composites such as compressive strength, flexural strength, impact strength etc. of the composites are also greatly enhanced by the weight percentage of $\mathrm{Al}_{2} \mathrm{O}_{3}$ with respect to thickness of specimen. 
Use of $15 \%$ wt. Aluminium Oxide $\left(\mathrm{Al}_{2} \mathrm{O}_{3}\right)$ in Glass fiber reinforced composite shows highest brittleness nature compared to 5 and $10 \%$ wt. reinforced.

Industry Importance: At present Glass fiber reinforced is a artificial product can be used for industrial application like manufacturing product, door and automotive industry in addition to solving environmental problems related to the disposal of product.

$10-15 \%$ Aluminium oxide $\left(\mathrm{Al}_{2} \mathrm{O}\right)$ reinforced having high impact resistance than $5 \%$ reinforced Aluminum oxide.

\section{REFERENCES}

1. Mr. Ravindra Mamgain ${ }^{1}$, Dr. Alakesh Manna $^{2}$, Dr. K.K.S MER ${ }^{3}$, Mr. Ashish Chauhan $^{4}$ Effect of Volume fraction $(\mathrm{Al} 2 \mathrm{O} 3+\mathrm{SiC}) \mathrm{p}$ on the Mechanical properties of Al (6061) Hybrid Metal Matrix Composite. [2015].

2. MD Nadeem $\mathbf{M}^{1}, \mathrm{~K}$, Chandrashekara $^{2}$ yathisha $\mathrm{N}^{3}$, Rudramurthy ${ }^{4}$. Study of the effects of carbon and glass fiber reinforcement and other fillers on elevated temperature resistant properties of ER matrix composites [2014].

3. K. Devendra ${ }^{1}$, T. Rangaswamy ${ }^{2}$. Strength Characterization of E-glass Fiber Reinforced Epoxy Composites with Filler Materials[2013].

4. Asutosh panda. A study on thermal conductivity of Epoxy / $\mathrm{Al}_{2} \mathrm{O}_{3}$ composites [2013].

5. S.Prabhakaran ${ }^{1}$, M.senthil Kumar. Development of Glass Fiber Reinforced Polymer Composite Ceiling Fane Blade [2012].

6. D. Abdul Budan Department of Mechanical Engineering, U.B.D.T. College of Engineering, Davangere - 577 004, India ( J. Machining and Machinability of Materials, Vol. 10, Nos. 1/2, 2011) "Comparative study on the machinability aspects of aluminium silicon carbide and aluminium - graphite - silicocarbide hybrid composites"

7. M. Asif, K. Chandra, P . S. Misra Department of Metallurgical and Materials Engineering Indian Institute of Technology Roorkee, Roorkee - 247667 (INDIA) (Journal of Minerals \& Materials Characterization \& Engineering, Vol. 10, No.14, pp.1337-1344, 2011) "Development of Aluminium Based Hybrid Metal Matrix Composites for Heavy Duty Applications"

8. Biswas S., Kindo S., Patnaik A., (2011). Effect of Length on Coir Fibre Reinforced Epoxy Composites, Fibre and Polymers 12, pp. $73-78$

9. Manoj Singla1, D. Deepak Dwivedi1, Lakhvir Singh2, Vikas Chawla3 Department of Mechanical Engineering India ( Journal of Minerals \& Materials Characterization \& Engineering, Vol. 8, No.6, pp 455-467, 2009) "Development of Aluminium Based Silicon Carbide Particulate Metal Matrix Composite"

10. Eun-Sung Lee, Sang-Mock Lee, Daniel J. Shanefield and W.Roger Cannon, Enhanced Thermal Conductivity of Polymer Matrix Composite Via High Solids Loading of Aluminium Nitride in Epoxy Resin, J. Am. Ceram. Soc.,91[4] (2008) 1169-1174.

11. Hisyam Noor, Mohamed Noor, and Shahril Osman Mohd. Mechanical Properties of Coir Fiber Reinforced Polypropylene Composites. Journal of Polymers and the Environment, 13-22; 139-149(2006).

12. Mehta N.M, Parsania P.H. Fabrication and evaluation of some mechanical and electrical properties of jute-biomass based hybrid composites. Journal of Applied Polymer Science, May [2006]. 
13. K. Jung-il, P.H. Kang and Y.C. Nho, Positive temperature coefficient behavior of polymer composites having a high melting temperature, J. Appl. Polym. Sci., 92 (2004) 394-401

14. H.S. Tekce, D. Kumlutas and I.H. Tavman, Determination of the Thermal Properties of Polyamide-6 (Nylon6)/Copper Composite by Hot Disk Method, In: Proceedings of the 10th Denizli Material Symposium, (2004) 296304.
15. I.Yamamoto, T. Higashihara and T. Kobayashi, Effect of silica-particle characteristics on impact/usual fatigue properties and evaluation of mechanical characteristics of silicaparticle epoxy resins, JSME Int. J., 46 (2) (2003) 145153.

16. H. Wang, Y. Bai, S. Lui, J. Wu and C.P. Wong, Combined effects of silica filler and its interface in epoxy resin, Acta Mater., 50 (2002) 4369-4377. 